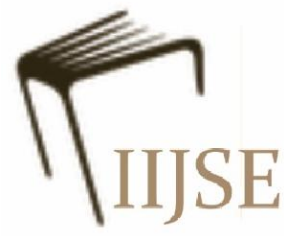

\title{
MEKANISME TRANSMISI KEBIJAKAN MONETER SYARIAH
}

\author{
Fitri Zaelina ${ }^{1}$ \\ Universitas Islam Negeri Raden Intan \\ zaelina.09@gmail.com
}

\begin{abstract}
Abstrak
Kata kunci:

UU No.3 Tahun 2004 menyebutkan bahwa Bank Indonesia diberi amanah sebagai otoritas moneter ganda yang dapat menjalankan kebijakan

Kebijakan

Moneter Syariah, moneter konvensional maupun syariah. Maka dari itu isu mekanisme transmisi kebijakan moneter syariah menjadi sangat penting. Penelitian ini bertujuan untuk mengidentifikasi proses transmisi moneter syariah di indonesia. Data yang digunakan dalam penelitian ini merupakan data time

Mekanisme

Transmisi, VAR series/ runtut waktu bulanan dari bulan januari 2006 hingga april 2016. Metode analisis yang digunakan adalah Vector Auto Reression (VAR). Hasil peneltian menunjukkan bahwa 1) alur transmisi kebijakan moneter syariah dengan tujuan akhir output menunjukkan kesinambungan jalur imbal hasil dari margin acuan SBIS sampai ke output; 2) guncangan SBIS, PLS, Financing direspon positif oleh output (IPI) sedangkan guncangan PUAS direspon negatif oleh output (IPI); dan 3) semua variabel BIRATE, SBIS, PUAS, PLS dan FINC berkontribusi terhadap pertumbuhan ekonomi dan pengurangan inflasi.
\end{abstract}

\begin{abstract}
Keywords:

Sharia Monetary

Act No. 3 of 2004 states that Bank Indonesia is entrusted as a dual monetary authority that can carry out conventional and 19yariah monetary policies. Therefore the issue of sharia monetary policy transmission mechanism becomes very important. This study aims to identify the process

Police,

Transmission of monetary transmission of sharia in Indonesia. The data used in this study is the time series data / monthly time series from January 2006 to April 2016. The analysis method used was Vector Auto Reression (VAR). The result of the research shows that 1) the sharia monetary policy Mechanism, VAR transmission flow with the final goal of the output shows the continuity of the yield path from the SBIS reference margin to the output; 2) SBIS shock, PLS, Financing were responded positively by output (IPI) while PUAS shocks responded negatively by output (IPI); and 3) all BIRATE, SBIS, PUAS, PLS and FINC variables contribute to economic growth and inflation reduction.
\end{abstract}




\section{A. Pendahuluan}

Kebijakan moneter merupakan salah satu kebijakan makroekonomi yang digunakan oleh bank sentral untuk mencapai tujuan akhir berupa stabilitas harga, pertumbuhan ekonomi, kesempatan kerja, keseimbangan neraca pembayaran. Kestabilan harga ialah prasyarat bagi pertumbuhan ekonomi yang berkesinambungan yang dapat memberikan manfaat untuk peningkatan kesejahteraan masyarakat.

Agar kebijakan moneter mencapai tujuan inflasi, maka dibutuhkan mekanisme jalur yang disebut sebagai mekanisme transmisi kebijakan moneter. Mekanisme transmisi adalah saluran yang menghubungkan antara kebijakan moneter dengan perekonomian (Pohan, 2008). Pada dasarnya mekanisme transmisi kebijakan moneter ialah bagaimana menghubungkan sektor moneter dengan sektor riil.

Pada perekonomian tradisional, dimana peran perbankan dominan dan produknya masih sederhana, peranan saluran uang juga masih dominan dengan pola hubungan antar aktivitas ekonomi relatif stabil. Namun, dengan semakin berkembangnya perbankan dan pasar keuangan, semakin banyak pula produk keuangan dengan jenis transaksi yang semakin bervariasi. Demikian juga dengan perekonomian yang terbuka, perkembangan ekonomi dan keuangan di suatu negara akan dipengaruhi oleh perkembangan ekonomi dan keuangan negara lain. Dengan demikian, peranan saluran lain seperti suku bunga, kredit, dan nilai tukar menjadi semakin penting. Selain itu, peranan saluran harga aset lainnya, seperti obligasi dan saham, dan saluran ekspektasi juga perlu diperhatikan (Warjiyo, 2004).

Dengan menerapkan dual banking system mekanisme transmisi kebijakan moneter semakin berkembang dan kompleks. UU No.3 Tahun 2004, bahwa Bank Indonesia (BI) diberi amanah sebagai otoritas moneter ganda yang menjalankan kebijakan moneter konvensional dan syariah. Ascarya (2012) menyatakan kebijakan moneter untuk 'pengurangan inflasi' dengan pola syariah lebih efektif daripada pola konvensional. Variabel konvensional yang utamanya adalah sektor finansial, secara alamiah memicu inflasi dan menghambat pertumbuhan ekonomi. Sedangkan variabel syariah yang utamanya adalah sektor rill, secara alamiah tidak memicu inflasi dan mendorong pertumbuhan ekonomi.

Pratama (2013) menemukan, instrumen kebijakan moneter syariah ialah instrumen yang tepat dalam mengendalikan tingkat inflasi. Sri Hernianingrum dan Imronjana 
(2016) juga menyimpulkan bahwa instrumen moneter syariah mengindikasikan adanya potensi pertumbuhan output dan menahan laju inflasi.

Perbedaan penelitian ini dengan penelitian sebelumnya yaitu lamanya periode yang digunakan yaitu 130 bulan dari bulan januari 2006 sampai oktober 2016. Dalam penelitian ini penyusun juga mengidentifikasi proses transmisi moneter syariah melalui jalur bagi hasil dan dampak kebijakan moneter syariah terhadap sasaran akhir yaitu pertumbuhan ekonomi dan inflasi.

\section{B. Kajian Literatur}

\section{Kebijakan Moneter}

Kebijakan moneter merupakan kebijakan otoritas moneter atau bank sentral dalam bentuk pengendalian besaran moneter untuk mencapai perkembangan kegiatan pereknomian yang diinginkan, yakni stabilitas ekonomi makro yang antara lain dicerminkan oleh stabilitas harga (inflasi rendah), membaiknya perkembangan output rill (pertumbuhan ekonomi), serta luasnya lapangan/kesempatan kerja yang tersedia. (Bank Indonesia, 2003)

2. Kebijakan Moneter dalam Ekonomi Makro

Upaya mencapai tingkat pertumbuhan ekonomi yang tinggi secara berkelanjutan dengan tetap mempertahankan kestabilan harga. Untuk mencapai tujuan tersebut Bank Sentral atau Otoritas Moneter berusaha mengatur keseimbangan antara persediaan uang dengan persediaan barang agar inflasi dapat terkendali, tercapai kesempatan kerja penuh dan kelancaran dalam pasokan/distribusi barang. Kebijakan moneter digolongkan menjadi dua, yaitu:

a. Kebijakan Moneter Ekspansif

b. Kebijakan Moneter Kontraktif

Kebijakan moneter yang ditetapkan oleh Bank Sentral berupa kebijakan kuantitatif dan kualitatif.

a. Kebijakan Kuantitatif

1) Open Market Operation

2) Reserve Requirement

3) The Discount Rate

b. Kebijakan Kualitatif

1) Selective Credit Control

2) Moral Suasion

3. Instrumen Penendalian Moneter

Dalam pelaksanaan kebijakan moneter, bank sentral menggunakan berbagai piranti sebagai instrumen dalam mencapai sasaran. Diantara instrumen itu berupa cadangan wajib (reserve requirement), operasi pasar terbuka (open market operation), fasilitas diskonto (discount policy), dan imbauan (moral suasion). (Pohan, 2008) 
4. Mekanisme Transmisi Kebijakan Moneter

Mekanisme transmisi kebijakan moneter pada dasarnya menggambarkan kebijakan moneter yang ditempuh bank sentral mempengaruhi aktivitas ekonomi dan keuangan sehingga pada akhirnya dapat mencapai tujuan akhir yang ditetapkan.

Di bidang keuangan, kebijakan moneter berpengaruh terhadap perkembangan suku bunga, nilai tukar, dan harga saham disamping volume dana masyarakat yang disimpan di bank, kredit yang disalurkan bank kepada dunia usaha, penanaman dana pada obligasi, saham maupun sekuritas lainnya. Di sektor ekonomi rill kebijakan moneter berpengaruh terhadap perkembangan konsumsi, investasi, ekspor dan impor, hingga pertumbuhan ekonomi dan inflasi yang merupakan sasaran akhir kebijakan moneter.

Mengingat kompleksitasnya, dalam teori ekonomi moneter, mekanisme transmisi kebijakan moneter sering disebut "black box" (mishkin: 1995), karena transmisi dimaksud dipengaruhi oleh tiga faktor, yaitu: (1) perubahan prilaku bank sentral, perbankan, dan para pelaku ekonomi dalam berbagai aktivitas ekonomi dan keuangannya; (2) lamanya tenggat waktu (time-lag) sejak tindakan otoritas moneter sampai sasaran akhir tercapai; serta (3) terjadinya perubahan saluran-saluran transmisi moneter itu sendiri sesuai dengan perkembangan ekonomi dan keuangan di negara yang bersangkutan. (Pohan, 2008)

Mekanisme bekerjanya perubahan BI rate sampai mempengaruhi inflasi sering disebut dengan istilah mekanisme transmisi kebijakan moneter (MTM). Mekanisme ini menggambarkan tindakan yang dilakukan BI melalui perubahanperubahan instrumen moneter dan target operasionalnya mempengaruhi berbagai variabel ekonomi dan keuangan yang kemudian berpengaruh terhadap tujuan akhir inflasi. Taylor (1995) menyatakan bahwa mekanisme transmisi kebijakan moneter merupakan jalur-jalur yang dilalui oleh kebijakan untuk dapat mempengaruhi sasaran akhir kebijakan moneter yaitu pendapatan nasional dan inflasi.

5. Tahapan Mekanisme Transmisi Kebijakan Moneter Syariah

Chapra dalam bukunya Towards a Just Monetary System (1985) menjelaskan pengaturan institusi keuangan Islam kontemporer tidak jauh berbeda dengan institusi keuangan konvensional yang sudah mapan, sehingga instrument- 
instrumen kebijakan moneter Islam juga banyak yang mirip dengan kebijakan moneter konvensional. Namun, karena cara kerja instrumen kebijakan moneter Islam memiliki persamaan dan perbedaan prinsip dengan konvensional, transmisi kebijakan moneter Islam dapat sama atau berbeda dengan transmisi kebijakan moneter konvensional.

Perkembangan teori moneter Islam selanjutnya juga belum ada yang menyinggung tentang transmisi kebijakan moneter Islam, termasuk pass-through atau jalur-jalurnya (lihat Siddiqui, 2008). Kebijakan moneter syariah berperan sebagai penyokong sektor riil. Untuk mencapai tujuan tersebut, uang dan lembaga perbankan adalah dua bagian terpenting yang harus digunakan untuk mencapai tujuan pencapaian kebijakan moneter syariah.

Chapra (1997) mengatakan, kebijakan moneter bertujuan untuk mencapai sosio ekonomi Islam. Antara lain yaitu:

a. Kesejahteraan ekonomi secara luas dengan berlandaskan full employment dengan tingkat pertumbuhan optimum;

b. Keadilan sosio-ekonomi dan pemerataan distribusi pendapatan dan kesejahteraan, salah satunya dapat dilakukan dengan mekanisme zakat yang baik dan benar;

c. Stabilitas nilai uang sehingga benarbenar menjadi medium of exchange yang benar-benar adil dan stabil;

d. Mobilisasi dan investasi modal untuk pembangunan ekonomi yang produktif dengan sistem pembagian yang adil untuk semua pihak yang terlibat;

e. Mewujudkan jasa-jasa lain, seperti pasar primer dan skunder untuk memenuhi kebutuhan akan pendanaan dan keuangan yang noninflationary untuk pemerintah.

Namun untuk mewujudkan tujuan-tujuan di atas, sangatlah kompleks dan memerlukan waktu. Mekanisme tersebut dimulai dari keputusan otoritas bank sentral selaku mitra pemerintah untuk melakukan perubahan instrumen moneter serta target operasional mempengaruhi berbagai variabel ekonomi dan keuangan. Mekanisme transmisi kebijakan moneter syariah di Indonesia dimulai pada tahun 2000 dengan menggunakan SWBI dan SBIS. Hingga pada tahun 2014 kembali BI telah mengeluarkan PBI No. 16 Tahun 2014 tentang Operasi Moneter Syariah (OMS). OMS dimaksud adalah bentuk pelaksanaan kebijakan moneter melalui kegiatan OPT dan penyediaan standing 
facilities dengan prinsip syariah. Maksud dari standing facilities syariah adalah fasilitas yang disediakan oleh BI kepada bank dalam rangka OMS melalui mekanisme lelang atau non-lelang.

\section{Metode Penelitian}

Penelitian ini menggunakan pendekatan kuantitatif. Data diambil dari laporan Statistik Perbankan Indonesia Bank Indonesia (SPI BI), Statistik Perbankan Syariah Bank Indonesia (SPS BI), Statistik Ekonomi dan Keuangan Indonesia BI (SEKI BI) dan Badan Pusat Statistik (BPS). Data penelitian ini merupakan data time series/ runtut waktu bulanan dari bulan januari 2006 hingga april 2016. Variabel-variabel yang digunakan dalam penelitian ini adalah sebagai berikut:

1. BIRATE: Tingkat suku bunga BI

2. SBIS: Policy Rate perbankan syariah berupa tingkat bonus SWBI dan tingkat fee SBIS

3. PUAS: Tingkat bagi hasil pasar uang antar bank Syariah

4. PLS: Tingkat bagi hasil pembiayaan bank Syariah

5. FINC: Total pembiayaan bank Syariah

6. IPI: Industrial Production Index adalah proxy dari pendapatan nasional

7. IHK: merupakan indikator yang digunakan untuk mengukur tingkat inflasi
Penelitian ini menggunakan analisis Vector Auto Regression (VAR) untuk mengelola data, jika data yang digunakan stasioner dan tidak terkointegrasi, atau dilanjutkan dengan metode Vector Error Correction Model (VECM) jika data yang digunakan stasioner dan terdapat kointegrasi.

\section{Hasil dan Pembahasan}

1. Uji Stasioneritas Data Time Series

Tabel 4.1. Hasil Pengujian Nonstasioneritas Pada Tingkat Level

\begin{tabular}{|c|c|c|c|c|c|}
\hline \multirow{2}{*}{ Variabel } & \multirow{2}{*}{$\begin{array}{c}\text { ADF } \\
\text { Statistic }\end{array}$} & \multicolumn{3}{|c|}{ Nilai Kritis Mc Kinnon } & \multirow{2}{*}{ Prob } \\
\hline & & $1 \%$ & $5 \%$ & $10 \%$ & \\
\hline BI Rate & -3.41203 & -3.48245 & -2.88429 & -2.57898 & 0.0123 \\
\hline SBIS & -2.476799 & -3.48655 & -2.88607 & -2.57993 & 0.1237 \\
\hline PUAS & -2.998033 & -3.48204 & -2.88411 & -2.57888 & 0.0377 \\
\hline PLS & -1.612254 & -3.48162 & -2.88393 & -2.57879 & 0.4734 \\
\hline FINC & -1.498233 & -3.48288 & -2.88448 & -2.57908 & 0.5314 \\
\hline $\mathrm{IHK}$ & -1.575767 & -3.48162 & -2.88393 & -2.57879 & 0.4920 \\
\hline IPI & -0.877375 & -3.48245 & -2.88429 & -2.57898 & 0.7926 \\
\hline
\end{tabular}

Sumber: data skunder diolah (2016)

Hasil pengujian akar unit menunjukkan bahwa hanya variabel BI Rate dan PUAS yang stasioner sedangkan variabel SBIS, FINC, PLS, IHK, IPI tidak stasioner di tingkat level pada taraf nyata 5\%. Hal ini dikarenakan nilai absolut ADF variabelvariabel tersebut lebih kecil dibanding dengan nilai kritis Mac Kinnon.

$\begin{array}{lrrr}\text { Tabel 4.2. } & \text { Hasil Pengujian } & \text { Non- } \\ \text { stasioneritas } & \text { Pada } & \text { Tingkat First } \\ \text { Difference. } & & & \end{array}$

\begin{tabular}{|l|c|c|c|c|c|}
\hline \multirow{2}{*}{ Variabel } & ADF & \multicolumn{3}{|c|}{ Nilai Kritis Mc Kinnon } & \multirow{2}{*}{ Prob } \\
\cline { 3 - 5 } & Statistic & $\mathbf{1 \%}$ & $\mathbf{5 \%}$ & $\mathbf{1 0 \%}$ & \\
\hline BI Rate & -3.689472 & -3.48245 & -2.88429 & -2.57898 & 0.0053 \\
\hline SBIS & -6.932919 & -3.48331 & -2.88467 & -2.57918 & 0.0000 \\
\hline
\end{tabular}




\begin{tabular}{|l|l|l|l|l|l|} 
PUAS & -15.25155 & -3.48204 & -2.88411 & -2.57888 & 0.0000 \\
\hline PLS & -11.25467 & -3.48204 & -2.88411 & -2.57888 & 0.0000 \\
\hline FINC & -3.288864 & -3.48288 & -2.88448 & -2.57908 & 0.0174 \\
\hline IHK & -13.55758 & -3.48204 & -2.88411 & -2.57888 & 0.0000 \\
\hline IPI & -11.77563 & -3.48245 & -2.88429 & -2.57898 & 0.0000 \\
\hline
\end{tabular}

Sumber: data skunder diolah (2016)

Hasil pengujian akar unit menunjukkan

bahwa semua variabel yang digunakan

dalam penelitian ini telah stasioner pada

tingkat first difference. Ini dikarenakan

nilai absolut ADF semua variabel

tersebut lebih besar dari nilai kritis Mac

Kinnon pada taraf nyata $5 \%$.

2. Penetapan Lag Optimal

Tabel 4.2. Hasil Pengujian Lag Optimal

\begin{tabular}{|c|l|r|}
\hline Lag & \multicolumn{1}{|c|}{ AIC } & \multicolumn{1}{|c|}{ SIC } \\
\hline 1 & 7.107671 & $7.922225^{*}$ \\
\hline 2 & $7.101782 *$ & 8.73089 \\
\hline 3 & 7.222673 & 9.666336 \\
\hline 4 & 7.390524 & 10.64874 \\
\hline 5 & 7.530034 & 11.60281 \\
\hline
\end{tabular}$\quad$\begin{tabular}{|c|r|r|r|}
\hline Lag & \multicolumn{1}{|c|}{ AIC } & \multicolumn{1}{c|}{ SIC } \\
\hline 1 & 6.067519 & $6.882073 *$ \\
\hline 2 & 6.049964 & 7.679073 \\
\hline 3 & 6.081433 & 8.525096 \\
\hline 4 & $5.932830 *$ & 9.191047 \\
\hline 5 & 6.187955 & 10.26073 \\
\hline
\end{tabular}

Sumber: data skunder diolah (2016)

Dalam penelitian ini lag optimal yang

digunakan adalah 1 . Hal ini dapat dilihat

dari hasil penetapan lag optimal pada

Tabel 4.2

\section{Uji Kointegrasi}

Tabel 4.3. HasiUji Kointegrasi.

Unrestricted Cointegration Rank Test (Trace)

\begin{tabular}{ccccc}
\hline \hline $\begin{array}{c}\text { Hypothesized } \\
\text { No. of CE(s) }\end{array}$ & Eigenvalue & $\begin{array}{c}\text { Trace } \\
\text { Statistic }\end{array}$ & $\begin{array}{c}0.05 \\
\text { Critical Value }\end{array}$ & Prob.** \\
\hline \hline None * & 0.359091 & 171.1331 & 125.6154 & 0.0000 \\
At most 1 & 0.255962 & 115.5247 & 95.75366 & 0.0011 \\
At most 2 & 0.203502 & 78.56677 & 69.81889 & 0.0085 \\
At most 3 & 0.154486 & 50.12549 & 47.85613 & 0.0301 \\
At most 4 & 0.124589 & 29.14920 & 29.79707 & 0.0593 \\
At most 5 & 0.084578 & 12.51642 & 15.49471 & 0.1338 \\
At most 6 & 0.011692 & 1.470171 & 3.841466 & 0.2253 \\
\hline \hline
\end{tabular}

Trace test indicates 4 cointegrating eqn(s) at the 0.05 level

* denotes rejection of the hypothesis at the 0.05 level

**MacKinnon-Haug-Michelis (1999) p-values

\begin{tabular}{ccccc} 
Unrestricted Cointegration Rank Test (Maximum Eigenvalue) \\
\hline \hline $\begin{array}{c}\text { Hypothesized } \\
\text { No. of CE(s) }\end{array}$ & Eigenvalue & $\begin{array}{c}\text { Max-Eigen } \\
\text { Statistic }\end{array}$ & $\begin{array}{c}0.05 \\
\text { Critical Value }\end{array}$ & Prob.** \\
\hline \hline None & 0.359091 & 55.60843 & 46.23142 & 0.0038 \\
At most 1 & 0.255962 & 36.95790 & 40.07757 & 0.1078 \\
At most 2 & 0.203502 & 28.44128 & 33.87687 & 0.1939 \\
At most 3 & 0.154486 & 20.97629 & 27.58434 & 0.2777 \\
At most 4 & 0.124589 & 16.63277 & 21.13162 & 0.1900 \\
At most 5 & 0.084578 & 11.04625 & 14.26460 & 0.1519 \\
At most 6 & 0.011692 & 1.470171 & 3.841466 & 0.2253 \\
\hline \hline
\end{tabular}

Max-eigenvalue test indicates 1 cointegrating eqn(s) at the 0.05 level

* denotes rejection of the hypothesis at the 0.05 level

**MacKinnon-Haug-Michelis (1999) p-values

Hasil output uji kointegrasi di atas dapat dilihat bahwa, beberapa nilai trace statistic $>$ critical value, begitu juga dengan nilai max eigen statistic sebesar 55.60843 lebih besar dari nilai critical value yaitu sebesar 46.23142, ini berarti bahwa dalam jangka panjang terdapat kointegrasi di dalam model persamaan tersebut. maka model yang digunakan ialah Vector Error Correction Model (VECM).

\section{Granger Causality}

Model yang diuji terbagi menjadi dua yaitu output dan inflasi. Hasil Granger Causality untuk alur transmisi kebijakan moneter dengan tujuan akhir output (IPI) dalam diagram 4.1 menunjukkan tidak adanya kesinambungan jalur imbal hasil dari margin acuan SBIS sampai ke output. SBIS mempengaruhi pasar keuangan ke PUAS dan Financing, PLS mempengaruhi PUAS, PUAS 
mempengaruhi Financing, dari financing

ke output.

Diagram 4.1

Alur Transmisi Moneter Syariah dari SBIS ke Output

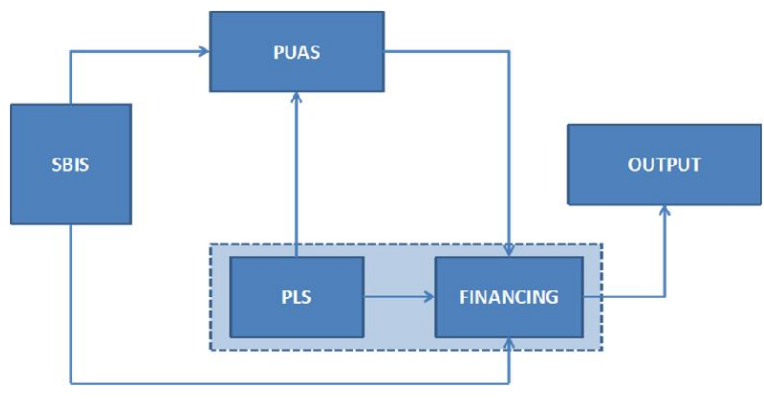

Tabel 4.4. Hasil Pengujian Granger

Causality Model Output

\begin{tabular}{|l|l|}
\hline \multicolumn{1}{|c|}{ Null Hypothesis: } & Prob. \\
\hline SBIS does not Granger Cause PUAS & 0.0871 \\
\hline SBIS does not Granger Cause LFINC & 0.0028 \\
\hline PLS does not Granger Cause PUAS & 0.0914 \\
\hline PUAS does not Granger Cause LFINC & 0.0001 \\
\hline PLS does not Granger Cause LFINC & 0.0004 \\
\hline LFINC does not Granger Cause IPI & 0.0086 \\
\hline
\end{tabular}

Sumber: data skunder diolah (2016)

Hasil Granger Causality menunjukkan adanya kesinambungan jalur imbal hasil dari margin dengan acuan SBIS sampai ke inflasi. SBIS mempengaruhi PUAS dan financing, sementara itu PLS mampengaruhi PUAS dan financing, dari PUAS ke financing, dari financing ke inflasi dan inflasi memberikan pengaruh balik ke financing.

Diagram 4.2

Alur Transmisi Moneter Syariah SBIS ke Inflasi

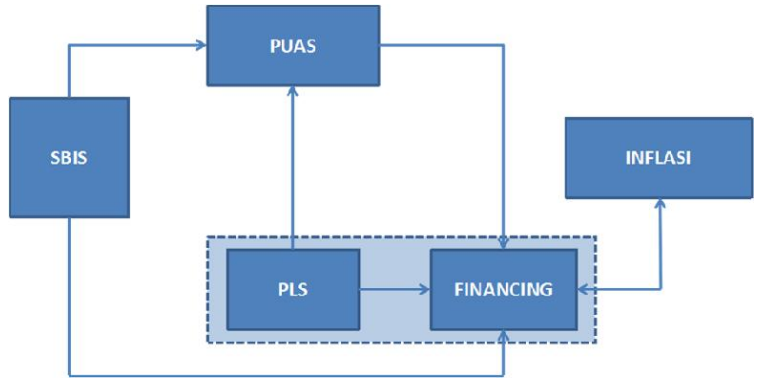

Tabel 4.5. Hasil Pengujian Granger

Causality Model Inflasi

\begin{tabular}{|l|c|}
\hline Null Hypothesis: & Prob. \\
\hline SBIS does not Granger Cause PUAS & 0.0871 \\
\hline SBIS does not Granger Cause LFINC & 0.0028 \\
\hline PLS does not Granger Cause PUAS & 0.0914 \\
\hline PUAS does not Granger Cause LFINC & 0.0001 \\
\hline PLS does not Granger Cause LFINC & 0.0004 \\
\hline IHK does not Granger Cause LFINC & 0.0238 \\
\hline LFINC does not Granger Cause IHK & 0.0088 \\
\hline
\end{tabular}

Sumber: data skunder diolah (2016)

Untuk alur transmisi kebijakan moneter dengan tujuan akhir output (IPI) melalui jalur acuan BI Rate ditunjukkan dalam diagram 4.3. Hasil menunjukkan tidak adanya kesinambungan jalur acuan BI Rate sampai ke output. BI Rate mempengaruhi PUAS dan PLS, dari PLS mempengaruhi PUAS dan financing, dari PUAS ke financing, serta dari financing ke output.

Diagram 4.3

Alur Transmisi Moneter Syariah BI Rate ke Output

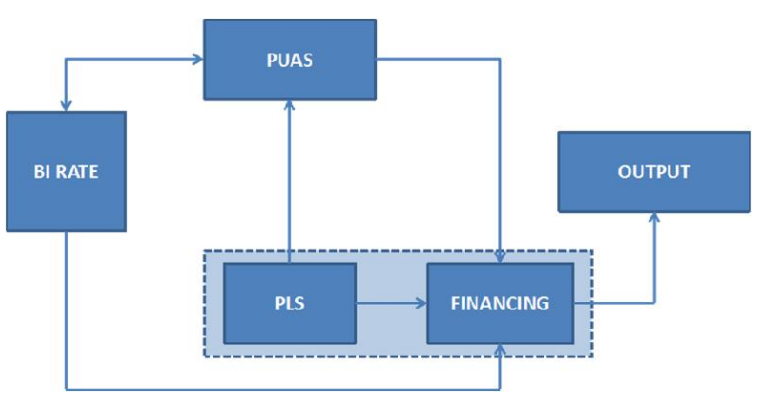


Tabel 4.6. Hasil Pengujian Granger

Causality Model Output

\begin{tabular}{|l|l|}
\hline \multicolumn{1}{|c|}{ Null Hypothesis: } & Prob. \\
\hline PUAS does not Granger Cause BIRATE & 0.0241 \\
\hline BIRATE does not Granger Cause PUAS & 0.0405 \\
\hline BIRATE does not Granger Cause LFINC & 0.0016 \\
\hline PLS does not Granger Cause PUAS & 0.0914 \\
\hline PUAS does not Granger Cause LFINC & 0.0001 \\
\hline PLS does not Granger Cause LFINC & 0.0004 \\
\hline LFINC does not Granger Cause IPI & 0.0086 \\
\hline
\end{tabular}

Sumber: data skunder diolah (2016)

Untuk alur transmisi kebijakan moneter

dengan tujuan akhir inflasi (IHK) melalui

jalur acuan BI Rate ditunjukkan dalam

diagram 4.4. BI Rate mempengaruhi

PUAS dan financing, dari PLS

mempengaruhi PUAS dan financing, dari

PUAS ke financing, serta PLS dan

financing mempengaruhi inflasi. Setelah

itu inflasi memberikan pengaruh balik ke financing.

Diagram 4.4

Alur Transmisi Moneter Syariah BI Rate ke Inflasi

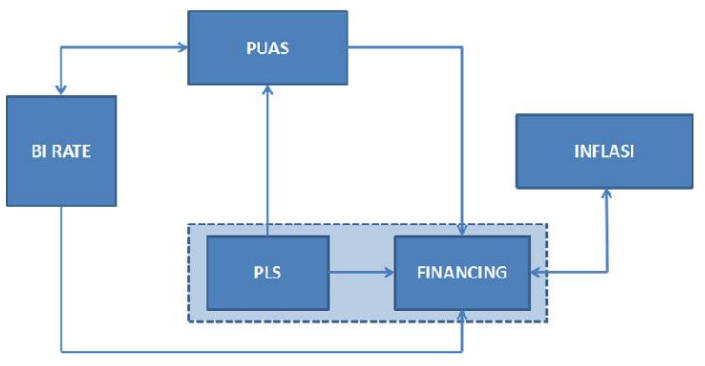

Tabel 4.7. Hasil Pengujian Granger

Causality Model Inflasi

\begin{tabular}{|l|l|}
\hline \multicolumn{1}{|c|}{ Null Hypothesis: } & Prob. \\
\hline PUAS does not Granger Cause BIRATE & 0.0241 \\
\hline BIRATE does not Granger Cause PUAS & 0.0405 \\
\hline BIRATE does not Granger Cause LFINC & 0.0016 \\
\hline PLS does not Granger Cause PUAS & 0.0914 \\
\hline PUAS does not Granger Cause LFINC & 0.0001 \\
\hline PLS does not Granger Cause LFINC & 0.0004 \\
\hline IHK does not Granger Cause LFINC & 0.0238 \\
\hline LFINC does not Granger Cause IHK & 0.0088 \\
\hline
\end{tabular}

5. Analisis Impulse Response Function (IRF)

Hasil IRF untuk alur transmisi kebijakan moneter model inflasi menunjukkan bahwa respon SBIS terhadap guncangan inflasi adalah negatif. Dengan kata lain, ketika SBIS mengalami guncangan (peningkatan) maka akan menurunkan inflasi. Lebih lanjut, dalam jangka panjang tidak terlihat tanda-tanda pergerakannya menuju keseimbangan atau mendekati angka nol (covergence) artinya perubahan SBIS akan tetap direspon oleh inflasi (IHK) karena efeknya yg permanen.

Jika melihat hasil IRF, Respon PUAS terhadap shock SBIS positif mulai dari awal periode hingga akhir periode. Respon positif ini menunjukkan ketika tingkat imbal hasil SBIS naik, hal ini akan diikuti pula oleh kenaikan tingkat imbal hasil PUAS. Sedangkan respon PUAS terhadap guncangan inflasi (IHK) adalah negatif, sederhanya, ketika PUAS mengalami guncangan peningkatan maka akan meningkatkan inflasi.

Respon PUAS terhadap pembiayaan bank syariah (FINC) adalah positif. Dengan kata lain, ketika PUAS mengalami guncangan peningkatan maka akan meningkatkan pembiayaan perbankan 
syariah. Respon PLS terhadap guncangan SBIS adalah positif.

Respon pembiayaan (FINC) terhadap SBIS negatif. Hal ini dapat disimpulkan bahwa apabila dana bank syariah disimpan melalui SBIS, akan semakin mempengaruhi penurunan pembiayaan bank syariah. Ini disebabkan apabila SBIS semakin besar jumlahnya, maka pembiayaan yang disalurkan oleh bank syariah akan menurun. Pada akhirnya berimplikasi pada manfaat ke sektor riil semakin berkurang.

Respon pembiayaan terhadap guncangan inflasi adalah negatif, artinya, semakin tinggi pembiayaan maka akan mampu menurunkan inflasi. Lebih lanjut, dalam jangka panjang tidak terlihat tanda-tanda pergerakannya menuju keseimbangan atau mendekati angka nol (covergence) artinya perubahan pembiayaan akan tetap direspon oleh inflasi (IHK) karena efeknya yg permanen.

6. Analisis Variance Decomposition (VD) Hasil penelitian menunjukkan bahwa periode pertama nilai output dominan mempengaruhi dirinya sendiri sebesar 98.23\%. Kemudian diikuti BIRATE, SBIS, financing, PLS dan PUAS. Periode kedua SBIS memberikan pengaruh yang dominan setelah output itu sendiri meskipun hanya sebesar $1.24 \%$. Periode ketiga hingga selanjutnya PUAS memberikan pengaruh yang dominan setelah variabel output itu sendiri yaitu sebesar $2.73 \%$ dan pada periode ke 12 sebesar $9.63 \%$.

Hasil VD menunjukkan variabel yang mempengaruhi volatilitas forcast error dari nilai output sesuai dengan urutan pengaruh terbesar adalah nilai output itu sendiri, PUAS, BIRATE, SBIS, PLS dan financing.

Penyumbang inflasi menunjukkan, pada periode pertama pengaruh terbesar adalah inflasi itu sendiri yaitu sebesar $94.46 \%$, dilanjutkan dengan financing, PUAS, BIRATE, PLS, dan SBIS. Pada periode ke 6 dan seterusnya PUAS memberikan pengaruh terbesar setelah inflasi yaitu sebesar $5.52 \%$ dan selanjutnya diikuti oleh financing, SBIS, BIRATE, PLS. Pada periode ke 12 PUAS memberikan pengaruh sebesar $13.61 \%$.

Secara umum hasil VD menunjukkan variabel yang mempengaruhi volatilitas forcast error dari nilai inflasi sesuai dengan urutan pengaruh terbesar adalah nilai inflasi itu sendiri, PUAS, financing, SBIS, BIRATE dan PLS. 


\section{E. Penutup}

1. Kesimpulan

a. Hasil granger causality alur transmisi kebijakan moneter syariah dengan tujuan akhir output menunjukkan adanya kesinambungan jalur imbal hasil dari margin acuan SBIS sampai ke output. Sedangkan alur transmisi kebijakan moneter dari SBIS dengan tujuan akhir inflasi (IHK) menunjukan tidak adanya kesinambungan jalur imbal hasil dari margin dengan acuan SBIS sampai ke inflasi.

b. Hasil IRF membuktikan, guncangan SBIS, PLS, Financing direspon positif output (IPI) sedangkan guncangan PUAS direspon negatif oleh output (IPI). Untuk hasil Impulse Responses model inflasi akibat guncangan SBIS, PUAS, PLS dan Financing direspon negatif oleh inflasi (IHK). Hal ini berarti ketika SBIS, PUAS, PLS, dan Financing mengalami guncangan (peningkatan) maka akan menurunkan inflasi dan meningkatkan output.

c. Hasil VD pada model inflasi dan output, semua variabel BIRATE, SBIS, PUAS, PLS dan FINC memiliki kontribusi terhadap pertumbuhan ekonomi dan pengurangan inflasi.
2. Saran

Penulis menyarankan kepada BI untuk mengoptimalkan penggunaan instrumen moneter syariah sehingga lebih efektif dalam meningkatkan output dan menurunkan inflasi. Serta senantiasa menjaga atau mengawasi efisiensi lembaga keuangan (perbankan) agar respon lembaga tersebut terhadap shock SBIS makin memperkuat terwujudnya sasaran akhir kebijakan moneter di Indonesia.

\section{F. Daftar Pustaka}

Ascarya. (2012). Alur Transmisi dan Efektivitas Kebijakan Moneter Ganda di Indonesia. Jurnal Ekonomi dan Perbankan, volume 14 Nomor 3.

Bank Indonesia . Statistik Perbankan Syariah Bank Indonesia. www.bi.go.id

Statistik Ekonomi dan Keuangan Indonesia Bank Indonesia. www.bi.go.id

. Undang-Undang Republik Indonesia Nomor 21 Tahun 2008 Tentang Perbankan Syariah. www.bi.go.id , Outlook Perbankan Syariah 2010. www.stas.ac.id

Bungin, Burhan. (2003). Analisis Data Penelitian Kualitatif. Jakarta: Raja Grafindo Persada.

Chapra, M. Umer. (1985). Towards a Just Monetary System. Leicester, UK: The Islamic Foundation. 
Chapra, M. Umer. 1997. Al-Qur'an Menuju Sistem Moneter yang Adil. Terjemah oleh Lukman Hakim, Yogyakarta: Dhana Bakti Prima Yasa.

Gujarati, D. (2003). Basic Econometrics, McGraw-Hill Companies, 8th Edition, USA.

Manurung, Mandala dan Pratama Rahardja (2004).Uang, Perbankan dan Ekonomi Moneter Kajian Kontektuan Indonesia). Jakarta: Fakultas Ekonomi Universitas Indonesia.

Maski, Ghozali. (2007). Transmisi Kebijakan Moneter: Kajian Teoritis dan Empiris. Malang: Badan Penerbit Fakultas Ekonomi Universitas Brawijaya.

Natsir, M. (2011). Analisis Empiris Efektivitas Mekanisme Transmisi Kebijakan Moneter di Indonesia melalui Jalur Suku Bunga (Interest Rate Channel) Periode 1990:22007:1. Majalah Ekonomi, Tahun XXI, (No. 2).

Pohan, Aulia. (2008). Potret Kebijakan Moneter Indonesia: Seberapa Jauh Kebijakan Moneter Mewarnai Perekonomian Indonesia. Jakarta: PT. Raja Grafindo Persada. . (2008). Kerangka Kebijakan Moneter dan Implementasinya di Indonesia. Jakarta: PT Raja Grafindo Persada.

Rusydiana, Aam Slamat, (2009). Mekanisme Transmisi Syariah Pada Sistem Moneter Ganda di Indonesia. Buletin Ekonomi dan Perbankan, April 2009.

Siddiqui, Shamin Ahmad. (2008). An Evaluation of Research on Monetary Policy and Stability of the Islamic Economic System. Paper presented at International Conference on Islamic
Economics: 30 Years of Research in Islamic Economics, Jeddah: KAAUIRTI, April.

Warjiyo, Perry. (2004). Mekanisme Transmisi Kebijakan Moneter di Indonesia. Seri Kebanksentralan No. 11. PPSK. Jakarta: Bank Indonesia.

Warjiyo, P dan Solikin. (2003). Kebijakan Moneter di Indonesia. Seri Kebanksentralan No. 6. PPSK. Jakarta: Bank Indonesia.

Winarno, W, W. (2009). Analisis Ekonometrika dan Statistik dengan Eviews. Yogyakarta: UPP STIM YKPN.

Widarjono, Agus. (2007). Ekonometrika. Edisi Kedua. Yogyakarta: Ekonisia.

Pengantar dan Aplikasinya.
Yogyakarta: UUP STIM YKPN. 